\title{
Trainee participation during screening colonoscopy does not affect ADR at subsequent surveillance, but may result in early follow-up
}

\section{(ㄷ)(1) $(-)$}

\section{Authors}

Alexander J. Eckardt' ${ }^{1}$, Joan Kheder ${ }^{2}$, Anjali Basil², Taryn Silverstein², Krunal Patel ${ }^{2}$, Mohamed Mahmoud², Yasir Al-Azzawi², Daniel Ellis², William Gillespie, Yoel Carrasquillo Vega², Sharina D. Person ${ }^{3}$, John M. Levey²

\section{Institutions}

1 Department of Gastroenterology and Hepatology, DKD Helios Klinik Wiesbaden, Wiesbaden, Germany

2 Division of Gastroenterology and Hepatology, UMass Memorial Medical Center, Worcester, Massachusetts, United States

3 Department of Population and Quantitative Health Sciences, University of Massachusetts Medical School, Worcester, Massachusetts, United States

submitted 25.3.2020

accepted after revision 30.7.2020

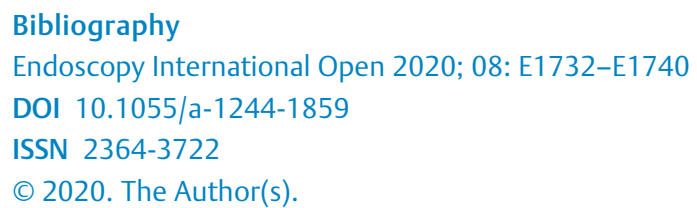
Commons Attribution-NonDerivative-NonCommercial License, permitting copying and reproduction so long as the original work is given appropriate credit. Contents may not be used for commecial purposes, or adapted, remixed, transformed or built upon. (https://creativecommons.org/licenses/by-nc-nd/4.0/)

Corresponding author

Alexander J. Eckardt, MD, Department of Gastroenterology and Hepatology, DKD Helios Klinik Wiesbaden, Aukammallee 33, 65191 Wiesbaden, Germany

Fax: +011 (49) 611577460

alexander.eckardt@helios-gesundheit.de

\section{ABSTRACT}

Background and study aims Training future endoscopists is essential to meet rising demands for screening and surveillance colonoscopies. Studies have shown conflicting results regarding the influence of trainees on adenoma detection rates (ADR). It is unclear whether trainee participation during screening adversely affects ADR at subsequent surveillance and whether it alters surveillance recommendations.

Patients and methods $A$ retrospective analysis of average-risk screening colonoscopies and surveillance exams over a subsequent 10-year period was performed. The initial inclusion criteria were met by 5208 screening and 2285 surveillance exams. Patients with poor preparation were excluded. The final analysis included 7106 procedures, including 4922 screening colonoscopies and 2184 surveillance exams. Data were collected from pathology and endoscopy electronic databases. The primary outcome was the ADR with and without trainee participation. Surveillance recommendations were analyzed as a secondary outcome.

Results Trainees participated in 1131 (23\%) screening and in $232(11 \%)$ surveillance exams. ADR did not significantly differ $(P=0.19)$ for screening exams with trainee participation (19.5\%) or those without (21.4\%). ADRs were higher at surveillance exams with (22.4\%) and without (27.5\%) trainee participation. ADR at surveillance was not adversely affected by trainee participation during the previous colonoscopy. Shorter surveillance intervals were given more frequently if trainees participated during the initial screening procedure $(P=0.0001)$.

Conclusions ADR did not significantly differ in screening or surveillance colonoscopies with or without trainee participation. ADR at surveillance was not adversely affected by trainee participation during the previous screening exam. However, trainee participation may result in shorter surveillance recommendations.

\section{Introduction}

Colorectal cancer is the third most common cancer in men and women in the United States [1]. Colonoscopy has emerged as the main diagnostic and therapeutic tool for the detection of colonic adenomas. It is estimated that identification and removal of colonic adenomas leads to a decrease in colorectal cancer incidence by $25 \%$ to $30 \%$ [2,3]. Training future endoscopists is essential to meet rising demands for colonoscopy [4]. Conflicting data about the influence of fellow participation 
during colonoscopy on adenoma detection rates (ADR) have been published. One meta-analysis showed neither an adverse nor a favorable effect of fellow participation on ADR overall [5]. However, this meta-analysis was limited by the inclusion of heterogeneous studies, mostly of small size. In a prospective study of our own group, ADR did not differ significantly, whether trainees participated during colonoscopy or not, but a trend towards lower ADRs in the presence of a trainee was observed [6]. However, this study did not include first-year trainees or subsequent surveillance exams. The aim of the current investigation was to answer the following questions: 1) Does the inclusion of first year trainees magnify a previously observed trend of lower ADRs in colonoscopies with trainee participation? 2) Is the effect of trainee participation the same for screening and surveillance exams? 3) Does the participation of trainees during the initial screening colonoscopy adversely affect ADR in subsequent follow-up exams? and 4) Does trainee participation affect follow-up recommendations?

\section{Patients and methods}

\section{Patients and study design}

A retrospective analysis of consecutive screening colonoscopies of average risk patients between January 2004 and December 2006 was performed at UMass Memorial Medical Center, Worcester, Massachusetts, United States. In addition, an analysis of subsequent surveillance procedures from the same patients was undertaken over a follow-up period of 10 years (until 2016, the year in which the retrospective data collection was started). Data were extracted from an electronic endoscopy database (Provation Medical, Minneapolis, Minnesota, United States) and an electronic pathology database. Only average-risk screening colonoscopies were included. Exclusion criteria were all other indications, such as surveillance (as an indication for the initial procedure), polyposis syndromes, gastrointestinal bleeding, hematochezia, inflammatory bowel disease, diarrhea, abdominal pain, anemia or weight loss. Patients with incomplete colonoscopies, as a result of poor bowel preparation or lack of intubation of the cecum, were also excluded from the final analysis.

The main exposure was trainee (fellow) participation during colonoscopy. All procedures with fellow participation (including first-year trainees) were included. The primary outcome was the ADR in screening and subsequent surveillance endoscopies, defined as the percentage of patients undergoing colonoscopy, who have at least one adenoma detected. As a secondary outcome we analyzed, whether follow-up recommendations were influenced by trainee involvement. Advanced adenoma detection rate (AADR), defined as colonoscopies with adenomas $\geq 1 \mathrm{~cm}$ in size, those with a villous component or high-grade dysplasia and polyp detection rates (PDR), including the total number of polyps removed during a single procedure, were also analyzed as secondary outcomes.

\section{Statistical analysis}

Statistical analysis was generated using SAS/STAT software, Version 9.4 of the SAS System for PC after initial data conversion into excel files. Continuous variables were summarized using mean and standard deviation, and categorical variables by using frequencies and percents. Differences between groups were compared by using $t$-tests to for continuous variables and Fisher's exact test or chi-square tests for categorical variables. Based on a two-group continuity corrected chisquare test of equal proportions, unequal n's, and alpha $=0.05$, a power calculation was performed. We calculated that 5000 colonoscopies needed to be included to achieve an $80 \%$ power to detect a difference in ADR of at least $5 \%$ between groups with or without trainee participation ( $20 \%$ of the sample performed with trainee present). Logistic regression analysis (unadjusted univariate and adjusted multivariable logistic regression) was used to test the association between the adenoma detection and other independent variables.

\section{Ethics}

The study was approved by the institutional review board (ethics committee) of the University of Massachusetts School of Medicine. The requirement for informed consent from the patients was waived owing to the retrospective nature of the study.

\section{Results}

\section{General characteristics of the study sample}

A total of 5208 colonoscopies met the initial inclusion criteria. Of these, 1217 (23.4\%) were performed with trainee participation and 3991 (76.6\%) were performed by the attending physicians alone. In addition, 2285 patients of the initial cohort also underwent subsequent surveillance exams at our institution. Therefore, a total of 7493 procedures were initially included in the study. After exclusion of incomplete exams, missing data, and patients with poor bowel preparation, 4922 screening colonoscopies remained. Of these, 2184 (44.4\%) had subsequent surveillance exams at our institution. Therefore, a total of 7106 procedures were included in the final analysis ( $\mathbf{F i g} \mathbf{1 a}$ and - Fig. 1b). The patient characteristics for procedures with and without trainee participation are listed in $>$ Table 1 for screening colonoscopies and $>$ Table 2 for surveillance colonoscopies and are subsequently explained in further detail.

\section{Initial screening colonoscopies}

There were no differences between both groups regarding procedure indication, patient age, gender or difficulty of the procedure. Bowel preparations affecting follow-up recommendations were found in similar percentages. Fair preparations were present in $11.2 \%$ of procedures with trainee participation and $10.0 \%$ of attending procedures, respectively. Preparation quality was not reported in $13.8 \%$ of procedures with fellow participation and $33.1 \%$ without fellow participation. Higher sedative doses were used when trainees were present during the procedure $(P<0.0001)$ without differences in associated complica- 


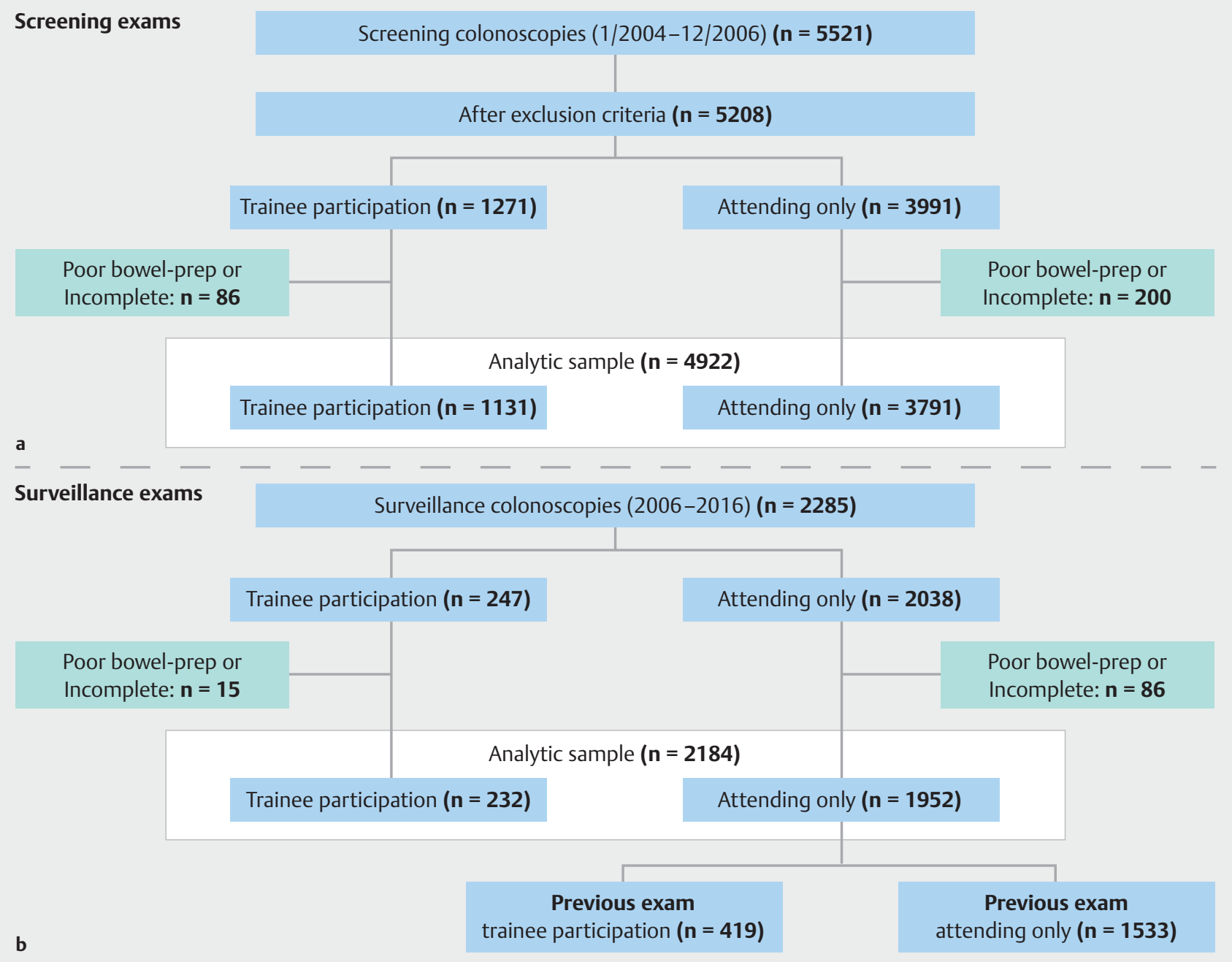

Fig. 1 Study inclusion flowchart. A total of 7106 colonoscopies were included in the final analysis. 4922 colonoscopies were performed for screening and 2184 for surveillance.

tions. Complete colonoscopies were achieved in $96.6 \%$ of procedures with trainee participation and $98.1 \%$ of attending-only procedures $(P=0.06)$.

\section{Subsequent surveillance colonoscopies}

All of these colonoscopies had "surveillance" as the primary indication. However, additional diagnoses, such as hematochezia, diarrhea or abdominal pain were mentioned in $54.9 \%$ of trainee reports and $39.7 \%$ of attending reports. There were no relevant differences between both groups regarding age, gender or difficulty of the procedure. Fair preparations were present in $17.8 \%$ of procedures with fellow participation and $14.3 \%$ of attending procedures, respectively. Similar to the previous screening procedures, higher sedative doses were used when trainees were present during the procedure $(P=0.0018)$ without differences in associated complications. Complete colonoscopies were possible in $95.6 \%$ of procedures with trainee participation and $97.1 \%$ of attending-only procedures $(P=0.29)$.

\section{ADR, AADR and PDR during screening and surveillance exams}

ADR in colonoscopies with or without fellow participation did not differ significantly in screening exams ( $>$ Table 3 ) or surveillance exams ( $>$ Table 4 ).

Initial screening colonoscopies

$A D R$, the $A A D R$ and PDR were not significantly different in screening colonoscopies with or without fellow participation ( $\triangleright$ Table 3). Overall, PDR and ADR did not differ significantly in colonoscopies with or without fellow participation ( $\downarrow$ Table 3 ). When fellows were involved during the procedure ADR was $19.5 \%$ compared with $21.4 \%$ in those procedures performed by the attending physician alone $(P=0.19)$. In male patients, the ADR was lower if a fellow was present (ADR 22.8\%) than in procedures without fellow participation (ADR 27.2\%), respectively $(P=0.036)$. However, multivariable analysis showed no effect of trainee participation, preparation quality, sedation or 
- Table 1 Patient and procedural characteristics in colonoscopies performed with and without trainee participation: initial screening colonoscopy $(n=5208)$.

\begin{tabular}{|c|c|c|c|}
\hline Characteristics & TP & AO & $P$ value \\
\hline \multicolumn{4}{|l|}{ Characteristics of the patient } \\
\hline - Age: Mean (SD) & $57.2(7.9)$ & $57.4(7.8)$ & 0.39 \\
\hline \multicolumn{4}{|l|}{ - Gender: \% (N) } \\
\hline - Female & $49.8(606)$ & $49.8(1989)$ & 0.98 \\
\hline - Male & $50.2(611)$ & $50.2(2002)$ & \\
\hline \multicolumn{4}{|l|}{ - Indication: \% (N) } \\
\hline - Screening & $100(1217)$ & $100(3991)$ & \\
\hline \multicolumn{4}{|c|}{ Characteristics of the procedure } \\
\hline \multicolumn{4}{|l|}{ - Level of difficulty: \%(N) } \\
\hline - Not difficult & $94.0(1134)$ & $93.8(3723)$ & 0.98 \\
\hline - Slightly difficult & $0.5(6)$ & $0.6(23)$ & \\
\hline - Moderately difficult & $2.8(34)$ & $2.7(108)$ & \\
\hline - Very difficult & $0.7(8)$ & $0.8(32)$ & \\
\hline - Not mentioned & $2.1(25)$ & $2.1(82)$ & \\
\hline \multicolumn{4}{|c|}{ - Quality of Preparation:1 \% (N) } \\
\hline - Excellent/Good & $68.4(830)$ & $51.9(2065)$ & $<0.001$ \\
\hline - Fair & $11.0(134)$ & $10.2(407)$ & \\
\hline - Not Mentioned & $13.8(167)$ & $33.1(1318)$ & \\
\hline \multicolumn{4}{|l|}{ - Complications ${ }^{2}$} \\
\hline - None & $99.5(1208)$ & $99.8(3975)$ & 0.5 \\
\hline - Cardiovascular & $0.3(3)$ & $0.08(3)$ & \\
\hline - Respiratory & $0.1(1)$ & $0.05(2)$ & \\
\hline - Perforation & $0.1(1)$ & $0.03(1)$ & \\
\hline - Other & $0.1(1)$ & $0.08(3)$ & \\
\hline - Complete exams: \% (N) & 96.6 & 98.1 & 0.06 \\
\hline - Terminal ileum & $40.5(487)$ & $35.7(1414)$ & \\
\hline - Cecum & $56.1(687)$ & $62.4(2473)$ & \\
\hline
\end{tabular}

TP, trainee present; AO, attending only.

${ }^{1}$ Poor preparations (exclusion criteria) or not well specified category not shown.

${ }^{2}$ Multiple responses were allowed. As a result, the $\mathrm{N}$ may add to more than the number of participants.

level of training (first-, second-, or third-year fellows) on ADR, whereas patient age and gender affected this outcome ( $\triangleright$ Table 5). There also was no significant difference in the advanced adenoma detection rate (AADR), regardless of whether a fellow participated (AADR $3.2 \%$ ) during the procedure or not (AADR $2.6 \%)$, respectively $(P=0.62)$. In addition, the total number of adenomas removed during procedures with adenoma detection was analyzed, which may serve as an indicator of complete
- Table 2 Patient and procedural characteristics in colonoscopies performed with and without trainee participation: Follow-up surveillance colonoscopy $(\mathrm{N}=2285)$.

\begin{tabular}{|c|c|c|c|}
\hline Characteristics & TP & AO & $P$ value \\
\hline \multicolumn{4}{|c|}{ Characteristics of the patient } \\
\hline - Age: Mean (SD) & $63.8(8.0)$ & $62.3(7.7)$ & 0.004 \\
\hline \multicolumn{4}{|l|}{ Gender: \% (N) } \\
\hline - Female & $42.9(106)$ & $47.8(972)$ & 0.15 \\
\hline - Male & $57.1(141)$ & $52.2(1061)$ & \\
\hline
\end{tabular}

Characteristics of the procedure

Level of difficulty: \% (N)

\begin{tabular}{l|l|l|l|}
\hline - Not Difficult & $91.9(227)$ & $90.5(1839)$ & 0.3
\end{tabular}

- Slightly Difficult $\quad 0.8(2)$

- Moderately Difficult $4.5(11) \quad 3.3(67)$

\begin{tabular}{l|l|l} 
- Very Difficult & $1.6(4)$ & $1.5(30)$
\end{tabular}

\begin{tabular}{l|l|l} 
- Not Mentioned $\quad 1.2(3)$ & $3.5(72)$
\end{tabular}

- Quality of preparation: ${ }^{1} \%(\mathrm{~N})$

\begin{tabular}{l|l|l|l|}
\hline - Excellent/Good & $72.9(180)$ & $56.7(1154)$ & $<0.0001$
\end{tabular}

\begin{tabular}{l|l|l} 
- Fair & $17.8(44)$ & $14.3(289)$
\end{tabular}

\begin{tabular}{l|l|l} 
- Not Mentioned $\quad 3.3(8)$ & $25(509)$
\end{tabular}

- Complications ${ }^{2}$

\begin{tabular}{l|l|l|l|}
\hline - None & $99.6(246)$ & $99.7(2026)$ & 0.85 \\
\hline
\end{tabular}

\begin{tabular}{l|l|l}
\hline - Cardiovascular & $0.4(1)$ & $0.2(4)$
\end{tabular}

\begin{tabular}{l|l|l} 
- Respiratory & $0(0)$ & $0.05(1)$
\end{tabular}

\begin{tabular}{l|l|l|}
\hline - Other & $0(0)$ & $0.1(2)$ \\
\hline
\end{tabular}

\begin{tabular}{lll|l|l|l} 
- Complete exams:\%(N) $95.6(236)$ & $97.1(1959)$ & 0.29
\end{tabular}

$\begin{array}{lll}\text { - Terminal ileum } \quad 36.7(93) & 44(888)\end{array}$

\begin{tabular}{l|l|l}
\hline - Cecum & $58.9(143)$ & $53.1(1071)$
\end{tabular}

TP, trainee present; $\mathrm{AO}$, attending only.

${ }^{1}$ Poor preparations (exclusion criteria) or not well specified category not shown.

${ }^{2}$ Multiple responses were allowed. As a result, the $\mathrm{N}$ may add to more than the number of participants.

detection of all relevant lesions in an individual patient. There was no significant difference in either group ( $>$ Table 6 ).

Follow-up (surveillance) colonoscopies

PDR and ADR also did not differ significantly in surveillance colonoscopies with or without fellow participation ( $>$ Table 4). However, PDR and ADR were higher in surveillance exams compared with screening exams. The mean ADR for surveillance colonoscopies was $22.4 \%$ if a fellow participated and $27.5 \%$ if it was performed by the attending physician alone $(P=0.1)$. Similar to the screening procedures, multivariable analysis showed no effect of trainee participation, preparation quality, sedation or level of training (first-, second-, or third-year fellows) on 
- Table 3 Yield of polyp or adenoma detection: initial colonoscopy $(n=4922)$.

\begin{tabular}{|l|l|l|l|}
\hline $\begin{array}{l}\text { Yield for polyps or } \\
\text { adenoma }\end{array}$ & $\begin{array}{l}\text { TP } \\
(\mathbf{n}=\mathbf{1 1 3 1 )}\end{array}$ & $\begin{array}{l}\text { AO } \\
(\mathbf{n = 3 7 9 1 )}\end{array}$ & P value \\
\hline $\begin{array}{l}\text { Polyp detection rate/ } \\
\text { PDR (\%) }\end{array}$ & 37.7 & 40.8 & 0.06 \\
\hline - Male & 42.9 & 47.6 & 0.049 \\
\hline - Female & 32.3 & 33.9 & 0.48 \\
\hline $\begin{array}{l}\text { Adenoma detection rate/ } \\
\text { ADR (\%) }\end{array}$ & 19.5 & 21.4 & 0.19 \\
\hline - Male & 22.8 & 27.2 & 0.036 \\
\hline - Female & 16.3 & 15.5 & 0.68 \\
\hline $\begin{array}{l}\text { Advanced adenoma } \\
\text { detection rate/AADR (\%) }\end{array}$ & 3.2 & 2.9 & 0.62 \\
\hline - Male & 3.5 & 3.4 & 0.92 \\
\hline - Female & 2.9 & 2.4 & 0.53 \\
\hline \begin{tabular}{l} 
TP, trainee present; AO, attending only. \\
\hline
\end{tabular} & & & \\
\hline
\end{tabular}

Table 4 Yield of polyp or adenoma detection: follow-up colonoscopy $(n=2184)$.

\begin{tabular}{|l|l|l|l|}
\hline $\begin{array}{l}\text { Yield for polyps or } \\
\text { adenoma }\end{array}$ & $\begin{array}{l}\text { TP } \\
\text { (n= 232) }\end{array}$ & $\begin{array}{l}\text { AO } \\
\text { (n=1952) }\end{array}$ & P value \\
\hline $\begin{array}{l}\text { Polyp detection rate/PDR } \\
\text { (\%) }\end{array}$ & 36.2 & 41.9 & 0.1 \\
\hline - Male & 41.7 & 48.5 & 0.14 \\
\hline - Female & 29 & 34.6 & 0.26 \\
\hline $\begin{array}{l}\text { Adenoma detection rate/ } \\
\text { ADR (\%) }\end{array}$ & 22.4 & 27.5 & 0.1 \\
\hline - Male & 28 & 33.4 & 0.22 \\
\hline - Female & 15 & 21.1 & 0.15 \\
\hline $\begin{array}{l}\text { Advanced adenoma detec- } \\
\text { tion rate/AADR (\%) }\end{array}$ & 0.9 & 1.9 & 0.26 \\
\hline - Male & 1.5 & 2.4 & 0.51 \\
\hline - Female & 0 & 1.3 & 0.25 \\
\hline
\end{tabular}

TP, trainee present; AO, attending only.

- Table 5 Multivariable analysis modeling ADR (primary endpoint).

\begin{tabular}{|c|c|c|c|c|}
\hline Initial colonoscopy (screening) effect & Point estimates & \multicolumn{2}{|c|}{$95 \%$ confidence limits } & $P$ value \\
\hline \multicolumn{5}{|l|}{ Trainee present } \\
\hline - Yes vs. No & 0.93 & 0.73 & 1.19 & 0.57 \\
\hline Age & 1.02 & 1.01 & 1.04 & 0.0004 \\
\hline \multicolumn{5}{|l|}{ Gender } \\
\hline - Female vs. Male & & 0.58 & 0.84 & 0.0002 \\
\hline \multicolumn{5}{|l|}{ Procedure difficulty } \\
\hline - Moderately/very difficult vs. slightly/not difficult & 0.7 & 0.5 & 1.84 & 0.89 \\
\hline \multicolumn{5}{|l|}{ Trainee year $^{1}$} \\
\hline - Second vs. First & 1.99 & 0.58 & 6.76 & 0.27 \\
\hline - Third vs. First & 1.8 & 0.54 & 5.98 & 0.34 \\
\hline \multicolumn{5}{|l|}{ Follow-up colonoscopy (surveillance) } \\
\hline Effect & Point estimates & \multicolumn{2}{|c|}{$95 \%$ confidence limits } & $P$ value \\
\hline \multicolumn{5}{|l|}{ Trainee present } \\
\hline - Yesvs. No & 0.95 & 0.56 & 1.6 & 0.83 \\
\hline Age & 1.053 & 1.031 & 1.076 & $<0.0001$ \\
\hline Gender & 0.76 & 0.56 & 1.04 & 0.08 \\
\hline \multicolumn{5}{|l|}{ - Female vs. Male } \\
\hline \multicolumn{5}{|l|}{ Procedure difficulty } \\
\hline - Moderately/very difficult vs. slightly/not difficult & 0.96 & 0.42 & 2.2 & 0.92 \\
\hline \multicolumn{5}{|l|}{ Trainee year $^{1}$} \\
\hline - Second vs. First & 0.25 & 0.04 & 1.5 & 0.13 \\
\hline . Third vs. First & 0.46 & 0.08 & 2.62 & 0.38 \\
\hline
\end{tabular}


- Table6 Number of adenomas found during procedures with adenoma detection.

Initial colonoscopy (screening)

\begin{tabular}{|l|l|l|}
\hline TP & AO & Pvalue \\
\hline$\%(n)$ & $\%(\mathbf{n})$ & \\
\hline
\end{tabular}

No. of adenomas

\begin{tabular}{|c|c|c|c|}
\hline .1 & $67.4(149)$ & $69.3(561)$ & 0.87 \\
\hline . 2 & $22.2(49)$ & $21(170)$ & \\
\hline " 23 & $10.4(23)$ & $9.8(79)$ & \\
\hline
\end{tabular}

Follow-up colonoscopy (surveillance)

\begin{tabular}{|l|l|l|}
\hline TP & AO & P value \\
\hline$\%(n)$ & $\%(\mathbf{n})$ & \\
\hline
\end{tabular}

No. of adenomas

\begin{tabular}{|l|l|l|l|}
\hline - 1 & $69.2(36)$ & $67.8(364)$ & 0.53 \\
\hline - 2 & $13.5(7)$ & $18.8(101)$ & \\
\hline - $\geq 3$ & $17.3(9)$ & $13.4(72)$ & \\
\hline
\end{tabular}

TP, trainee present; $\mathrm{AO}$, attending only

- Table 7 Yield of adenoma detection at follow-up colonoscopy (depending on trainee participation at the previous colonoscopy).

\begin{tabular}{|l|l|l|l|}
\hline $\begin{array}{l}\text { Yield for } \\
\text { adenoma }\end{array}$ & TP (at baseline) & AO (at baseline) & P value \\
\hline $\begin{array}{l}\text { Adenoma detec- } \\
\text { tion rate (\%) }\end{array}$ & $\mathbf{n}=\mathbf{4 1 9}$ & $\mathbf{n = 1 5 3 3}$ & \\
\hline & & $27.9(428 / 1533)$ & 0.44 \\
\hline TP, trainee present; AO, attending only & & \\
\hline
\end{tabular}

ADR, whereas patient age affected this outcome ( $\triangleright$ Table 5). AADR was $0.9 \%$ for colonoscopies with fellow participation and $1.9 \%$ for those without fellow participation $(P=0.26)$.

\section{Influence of trainee participation during the initial colonoscopy on ADR in subsequent follow-up exams}

In this subgroup analysis, we used the ADR at subsequent surveillance exams as a surrogate marker for missed lesions during the prior screening exam. In order to assess, whether trainee participation at the initial screening procedure affects ADR at subsequent follow-up colonoscopies, we analyzed surveillance exams that were performed by attending physicians only and compared the ADR, depending on whether a fellow was present during the previous screening procedure or not. A total of 1952 follow-up colonoscopies (surveillance exams) were performed by attending physicians alone. Of these, 419 patients had a previous colonoscopy with fellow participation and 1533 patients had previous colonoscopies without fellow participation ( $>$ Fig. 1). Fellow participation during screening colonoscopies did not significantly affect the ADR at subsequent surveillance ( Table 7).

\section{Effect of trainee-participation on follow-up recommendations}

\section{Initial screening colonoscopies}

Recommendations for follow-up were given in $98 \%$ of the initial screening colonoscopy reports, regardless of whether fellows participated (1108/1131 exams) or not (3733/3791 exams). Recommendations met current guidelines in $62.4 \%$ of the trainee procedures and $53.9 \%$ of attending-only procedures $(P=$ 0.0001). When follow-up recommendations deviated from guidelines, patients were asked to return earlier for surveillance in $57.6 \%$ of trainee procedures and $42.8 \%$ of attending-only procedures, respectively $(P=0.0001)$. When recommendations did not match with current guidelines, most patients were asked to return more than 4 years earlier than guidelines would have recommended ( $\triangleright$ Table 8 ).

\section{Follow-up (surveillance) colonoscopies}

Recommendations for follow-up were given in $91 \%$ of surveillance colonoscopy reports with fellow participation (212/232 exams) and $93 \%$ of those without fellow participation (1820/ 1952 exams). Recommendations met current guidelines in $58 \%$ of the reports, regardless of whether a fellow participated or not $(P=0.99)$. Again, when recommendations didn't match with current guidelines, most patients were asked to return earlier than guidelines would have recommended ( $>$ Table 8 ). Noted differences between procedures with or without trainee participation did not reach statistical significance $(P=0.57)$.

\section{Discussion}

To our knowledge, this is the first study to assess the influence of trainee participation on ADR during surveillance exams, following an initial cohort of average-risk screening colonoscopies. This study confirms that there is no significant difference in ADR during average-risk screening colonoscopies with or without trainee participation, even if exams with first-year fellows are included. Furthermore, trainee participation during the initial procedure does not lead to increased risk of adenoma detection (e.g. missed lesions) on follow-up exams. Adherence to current guidelines is significantly higher if trainees participate during the procedure. However, if recommendations deviated from guidelines, shorter surveillance intervals resulted from procedures with trainee participation.

This study confirms previous results from a smaller, prospective investigation by our group, indicating that trainee participation during screening colonoscopies does not adversely affect ADR, overall [6]. Other investigators have reported higher ADRs in the presence of trainees, although at least one study showed that this effect mostly accounts for small adenomas $[7,8]$. In addition, these initial studies involved small numbers of patients and/or included patients with a mixed bag of indications, such as screening, surveillance and other diagnostic reasons. This could explain, why ADRs were overall higher in these studies (ADR in attending procedures: $23-26 \%$ and ADR in fellow procedures $30 \%$ to $37 \%$ ), as compared to the current study (ADR in attending procedures: $21.4 \%$ and ADR in fellow proce- 
Table 8 Comparison of trainee status among those for whom endoscopy reports and guidelines don't match.

\begin{tabular}{|l|l|l|}
\hline Follow-up time on report & TP (at baseline) \% (n) & AO (at baseline) \% (n) \\
\hline Screening colonoscopies & $\mathrm{n}=417$ & $\mathrm{n}=1722$ \\
\hline 0-4 years earlier & $12.7(53)$ & $6.5(112)$ \\
\hline$>4$ years earlier & $44.8(187)$ & $36.3(625)$ \\
\hline 0-4 years later & $2.9(12)$ & $4.2(72)$ \\
\hline$>$ 4 years later & $0.2(1)$ & $0.06(1)$ \\
\hline Unknown & $39.3(164)$ & $(912)$ \\
\hline Surveillance colonoscopies & $\mathrm{n}=89$ & $\mathrm{n}=765$ \\
\hline 0-4 Years Earlier & $10.1(9)$ & $8.9(68)$ \\
\hline$>$ 4 years earlier & $33.7(30)$ & $38.8(297)$ \\
\hline 0-4 years later & $10.1(9)$ & $8.2(63)$ \\
\hline$>4$ years later & $0(0)$ & $1.8(14)$ \\
\hline Unknown & $46.1(41)$ & $42.2(323)$ \\
\hline TP, trainee present; AO, attending only. & & \\
\hline
\end{tabular}

dures $19.5 \%$ ), which only included average-risk screening colonoscopies. Although the ADRs in the current study appear comparatively low, they match quality standards at the time of study inclusion, as defined by the U.S. Multi-Society Task Force on Colorectal Cancer [9]. Quality measures such as ADR have been adjusted since then, owing to improved equipment and awareness of flat lesions, such as sessile serrated lesions, which have come into much higher focus in the last decade. However, any change or improvement over the years would have likely affected both, trainees and attending phyisicians in a similar way and therefore comparison of both groups would likely be similar today, despite overall higher ADRs [10].

The differences in ADRs between studies could also be explained by the fact that a pre-selection of attending physicians with high ADRs improved outcomes in previous investigations. Significant variations in ADRs are present among attending physicians and preselection of those with high colonoscopy performance (high-detectors) will likely lead to favorable results [11]. Such pre-selection did not occur in the current study. In addition, publication bias could have led to selection of studies with higher ADRs and positive outcomes. Previous studies, which showed no effect or a negative effect on ADRs with fellow involvement during colonoscopy, were only published as letters to the editor or brief correspondence $[12,13]$.

Previous investigations have also shown that higher levels of fellowship training are associated with improved ADRs, but participation of first-year fellows does not affect ADR negatively [14-16]. The latter finding was confirmed in the current study, showing no adverse effect of first-year trainees on ADR, which could be explained by the fact that first-year fellows frequently receive assistance by the attending physician in order to assure an appropriate quality of the exam.

This study also provides evidence that ADRs are generally higher in surveillance exams than in screening exams, a finding that has recently been recognized by others as well $[17,18]$. Importantly, this effect is similar for colonoscopies with and without trainee participation. It also shows that trainee participation during screening colonoscopy does not lead to an increased rate of missed adenomas, which otherwise likely would result in the detection of more advanced lesions during subsequent surveillance [19]. There was no difference in ADR and AADR during surveillance exams, regardless of trainee participation at the previous screening exam. This could be either explained by a similar detection of relevant adenomas during the initial screening procedure, or by the fact that shorter surveillance recommendations were frequently given if a fellow participated during the initial screening exam. However, the latter explanation seems less likely, as previous investigations have shown that ADR at surveillance is not higher if shorter intervals are chosen, than those recommended by guidelines [20].

Adherence to guideline recommendations at screening exams appears to be significantly better if trainees participated during the procedure. The adherence rate was $62.4 \%$ with trainee participation, as compared to the $53.9 \%$ in the attendingonly group. These adherence rates are comparable with the $58 \%$ to $64 \%$ reported in the literature for differing clinical scenarios [20-23]. The higher adherence rates in the trainee group could result from the fact that attending physicians in academic hospitals teach their trainees to adhere to guidelines, whenever optimal conditions are present. In contrast, it appears that attending physicians are slightly less stringent in the absence of a trainee.

As mentioned above, the lack of adherence to current guidelines appears to be a rather common phenomenon [24,25]. Studies have shown that such deviations can result from a lack of knowledge of current guidelines, but more frequently are caused by other factors, such as limited bowel preparation, difficult procedures, (e.g. formation or blind areas), disagreement 
with guideline recommendations or lower level of endoscopists' experience $[23,25]$. It seems intuitive that shorter intervals are frequently chosen, if bowel preparation is considered fair, rather than good or excellent [27]. However, a recent meta-analysis suggests that the impact of bowel preparation on missed lesions may be low, unless it is considered to be poor [28]. On the other hand, limited visualization can also occur in a clean colon, when a procedure is considered to be difficult, such as in the case of a tortuous colon with tight angulations, difficult sigmoid passage, or poor control of the endoscope in the in case of loop formation. As a result, longer insertion times appear to correlate with lower ADRs [11,29]. Such technical difficulties are more likely to result if endoscopists are inexperience. This could explain why shorter surveillance intervals were frequently chosen in the presence of a trainee in this study. However, as ADRs were neither affected by trainee participation in screening, nor surveillance exams, it is likely that the presence of an experienced physician can counteract any technical difficulty that may occur. In our opinion, the mere presence of a trainee during colonoscopy, therefore, should not alter surveillance recommendations.

The current study has several strengths. We included a large number of average-risk screening procedures in the initial cohort. This avoided potential bias from a mixed bag of indications and makes a potential type 2 error unlikely. It therefore provides realistic data regarding the ADR in the training setting. In addition, this is the first study to assess the effect of trainee participation on subsequent surveillance exams over a period of 10 years. It therefore provides indirect evidence that there is no increase of missed lesions in the presence of trainees. However, the retrospective design of this study also leads to some limitations. It is unclear to what extent attending physicians intervened during the procedures, what the intubation times and withdrawal times were during the procedures, and to what extent trainees were involved in individual exams. However, from our previous prospective investigation we learned that attending physicians took control of the exam in $17 \%$ of the cases. It is likely that the inclusion of first-year trainees leads to even higher "take-over" rates [6]. Furthermore, the same study showed a significant difference in cecal intubation times (mean: 3.5 minutes longer when trainees participated) and procedure times (mean: 6.2 minutes longer with trainee participation). Longer withdrawal times, frequent intervention by the attending physician or an extra pair of eyes during the procedure may alter ADR. In our teaching program it is standard procedure that involved trainees will begin the procedure under supervision and the attending physician takes control of the endoscope if difficulties occur. Beginners in the first year may therefore have limited "hands-on" time, whereas thirdyear fellows are expected to complete most of their procedures themselves. Although we cannot conclude which of the factors mentioned above are most important in terms of optimizing $A D R$ in the training setting, it is clear that the supervised approach to colonoscopy training avoids adverse outcomes regarding the ADR.

\section{Conclusion}

In conclusion, this study provides the first evidence that gastroenterology fellow participation during average-risk screening colonoscopies is not associated with an increased risk of missed adenomas at subsequent surveillance exams. Overall guideline adherence appears to be better when fellows participate during the procedure. However, if recommendations deviate from guidelines, trainee participation results in shorter surveillance intervals, despite the fact that quality measures do not seem to be affected by their participation.

\section{Competing interests}

The authors declare that they have no conflict of interest.

\section{References}

[1] Ward E, Sherman RL, Henley SJ et al. Annual Report to the Nation on the Status of Cancer, 1999-2015, Featuring Cancer in Men and Women ages 20-49. Natl Cancer Inst 2019; 111: 1279-1297

[2] Levin TR, Corley DA, Jensen CD et al. Effects of organized colorectal cancer screening on cancer incidence and mortality in a large community-based population. Gastroenterology 2018; 155: 1383-1391

[3] Kaminski MF, Wieszczy P, Rupinski M et al. Increased rate of adenoma detection associates with reduced risk of colorectal cancer and death. Gastroenterology 2017; 153: 98-105

[4] Joseph DA, Meester RG, Zauber AG et al. Colorectal cancer screening: Estimated future colonoscopy need and current volume and capacity. Cancer 2016; 122: 2479-2486

[5] Oh YS, Collins CL, Virani S et al. Lack of impact on polyp detection by fellow involvement during colonoscopy: a meta-analysis. Dig Dis Sci 2013; 58: 3413-3421

[6] Eckardt AJ, Swales C, Bhattacharya K et al. Does trainee participation during colonoscopy affect adenoma detection rates? Dis Colon Rectum 2009; 52: 1337-1344

[7] Rogart JN, Siddiqui UD, Jamidar PA et al. Fellow involvement may increase adenoma detection rates during colonoscopy. Am J Gastroenterol 2008; 103: 2841-2846

[8] Buchner AM, Shahid MW, Heckman MG et al. Trainee participation is associated with increased small adenoma detection. Gastrointest Endosc 2011; 73: 1223-1231

[9] Rex DK, Bond JH, Winawer S et al. Quality in the technical performance of colonoscopy and the continuous quality improvement process for colonoscopy: recommendations of the U.S. Multi-Society Task Force on Colorectal Cancer. Am J Gastroenterol 2002; 97: 12961308

[10] Rex DK, Schoenfeld PS, Cohen J et al. Quality indicators for colonoscopy. Gastrointest Endosc 2015; 81: 31-53

[11] Benson ME, Reichelderfer M, Said A et al. Variation in colonoscopic technique and adenoma detection rates at an academic gastroenterology unit. Dig Dis Sci 2010; 55: 166-171

[12] Friedman M, Arora G, Green J. Fellow involvement during colonoscopy does not reduce adenoma detection rate. Dig Dis Sci 2011; 56: 919

[13] Nishizawa T, Suzuki H, Takahashi M et al. Trainee participation during colonoscopy adversely affects polyp and adenoma detection rates. Digestion 2011; 84: 245-246 
[14] Peters SL, Hasan AG, Jacobson NB et al. Level of fellowship training increases adenoma detection rates. Clin Gastroenterol Hepatol 2010; 8: $439-442$

[15] Gianotti RJ, Oza SS, Tapper EB et al. A longitudinal study of adenoma detection rate in gastroenterology fellowship training. Dig Dis Sci 2016; 61: 2831-2837

[16] Qayed E, Shea L, Goebel S et al. Association of trainee participation with adenoma and polyp detection rates. World J Gastrointest Endosc 2017; 9: 204-210

[17] Mangas-Sanjuan C, Santana E et al. Variation in colonoscopy performance measures according to procedure indication. Clin Gastroenterol Hepatol 2019; 18: 1216-1223.e2. doi:10.1016/j. cgh.2019.08.035

[18] Anderson JC, Butterly LF, Goodrich M et al. Differences in detection rates of adenomas and serrated polyps in screening versus surveillance colonoscopies, based on the new hampshire colonoscopy registry. Clin Gastroenterol Hepatol 2013; 11: 1308-1312

[19] Mangas-Sanjuan C, Zapater P et al. Importance of endoscopist quality metrics for findings at surveillance colonoscopy: The detection-surveillance paradox. United European Gastroenterol J 2018; 6: 622-629

[20] Anderson JC, Baron JA, Ahnen DJ et al. Factors associated with shorter colonoscopy surveillance intervals for patients with low-risk colorectal adenomas and effects on outcome. Gastroenterology 2017; 152: 1933-1943

[21] van Kooten $\mathrm{H}$, de Jonge $\mathrm{V}$, Schreuders $\mathrm{E}$ et al. Awareness of postpolypectomy surveillance guidelines: a nationwide survey of colonoscopists in Canada. Can J Gastroenterol 2012; 2: 79-84
[22] Johnson MR, Grubber ], Grambow SC et al. Physician non-adherence to colonoscopy interval guidelines in the veterans affairs healthcare system. Gastroenterology 2015; 149: 938-951

[23] Shah TU, Voils Cl, McNeil R et al. Understanding gastroenterologist adherence to polyp surveillance guidelines. Am J Gastroenterol 2012; 107: $1283-1287$

[24] Saini SD, Nayak RS, Kuhn L et al. Why don't gastroenterologists follow colon polyp surveillance guidelines? Results of a national survey J Clin Gastroenterol 2009; 43: 554-558

[25] Schreuders E, Sint Nicolaas J, de Jonge $V$ et al. The appropriateness of surveillance colonoscopy intervals after polypectomy. Can J Gastroenterol 2013; 27: 33-38

[26] Kim ER, Sinn DH, Kim JY et al. Factors associated with adherence to the recommended postpolypectomy surveillance interval. Surg Endosc 2012; 26: 1690-1695

[27] Menees SB, Kim HM, Elliott EE et al. The impact of fair colonoscopy preparation on colonoscopy use and adenoma miss rates in patients undergoing outpatient colonoscopy. Gastrointest Endosc 2013; 78: 510-516

[28] Clark BT, Rustagi T, Laine L. What level of bowel prep quality requires early repeat colonoscopy: systematic review and meta-analysis of the impact of preparation quality on adenoma detection rate. Am J Gastroenterol 2014; 109: 1714-1723

[29] von Renteln D, Robertson DJ, Bensen S et al. Prolonged cecal insertion time is associated with decreased adenoma detection. Gastrointest Endosc 2017; 85: 574-580 